\title{
Test systems to study the structure and function of uncoupling protein 1: a critical overview
}

\section{Verena Hirschberg *, Tobias Fromme and Martin Klingenspor}

Molecular Nutritional Medicine, Else Kröner-Fresenius Zentrum, Technische Universität München, Freising, Germany

Edited by:

Patrick Seale, University of

Pennsy/vania, USA

\section{Reviewed by:}

Marta Letizia Hribal, University of

Catanzaro Magna Graecia, Italy

Maximilian Bielohuby,

Ludwig-Maximilians University,

Germany

\section{*Correspondence:}

Verena Hirschberg, Molecular

Nutritional Medicine, Else

Kröner-Fresenius Zentrum, Technische

Universität München,

Gregor-Mendel-Str. 2, 85350

Freising-Weihenstephan, Germany

e-mail: verena.hirschberg@

wzw.tum.de

\begin{abstract}
The discovery of active brown adipose tissue (BAT) in healthy adult humans has renewed interest in the biology of this organ. BAT is capable of distributing nutrient energy in the form of heat allowing small mammals to efficiently defend their body temperature when acutely exposed to the cold. On the other hand BAT might be a target for the treatment of obesity and related diseases, as its pharmacological activation could allow release of excess energy stored in white adipose tissue depots. Energy dissipation in BAT depends on the activity of uncoupling protein 1 (UCP1), therefore a BAT-based obesity therapy requires a detailed understanding of structure and function of UCP1. Although UCP1 has been in the focus of research since its discovery, central questions concerning its mechanistic function and regulation are not yet resolved. They have been addressed in native mitochondria but also in several test systems, which are generally used to lower inter-experimental variability and to simplify analysis conditions. Different test systems have contributed to our current knowledge about UCP1 but of course all of them have certain limitations. We here provide an overview about research on UCP1 structure and function in test systems. So far, these have nearly exclusively been employed to study rodent and not human UCP1. Considering that the amino acid sequence of mouse and human UCP1 is only $79 \%$ identical, it will be essential to test whether the human version has a similarly high catalytic activity, allowing a relevant amount of energy dissipation in human BAT. Besides the issue of comparable mechanistic function a sufficiently high expression level of human UCP1 is a further prerequisite for anti-obesity therapeutic potential. Treatments which induce BAT hyperplasia and UCP1 expression in humans might therefore be equally important to discover as mere activators of the thermogenic process.
\end{abstract}

Keywords: uncoupling protein 1, UCP1, mitochondria, brown adipose tissue

\section{INTRODUCTION}

Brown adipose tissue (BAT) is the exclusive site of cold induced non-shivering thermogenesis in mammals and combusts stored nutrient energy as heat (Smith, 1961). In cold exposed rodents, this powerful process can claim more than a quarter of cardiac output and more than half of total oxygen consumption, thereby facilitating heat dissipation up to nearly $500 \mathrm{~mW}$ per gram tissue (Foster and Frydman, 1978, 1979; Trayhurn and James, 1978; Puchalski et al., 1987). To achieve this unique capability, brown adipocytes are equipped with a specialized set of cellular features including a large number of mitochondria with dense cristae, multiple small lipid droplets providing high lipolytic rates, high nutrient uptake rates and many more. In the center of all these processes, however, a single essential protein facilitates the crucial mechanism of regulated mitochondrial proton leak across the inner membrane: uncoupling protein 1 (UCP1). Therefore, understanding the structure-function-relationship of UCP1 is of paramount importance to understand brown fat thermogenesis.

The significance of elucidating UCP1 function for biomedical applied science has recently been highlighted by the (re)discovery of active BAT in humans. Radiologists applying fluorodeoxyglucose positron emission tomography (FDG PET) combined with computerized tomography (CT) during tumor diagnosis accidentally visualized the in vivo distribution and activity of BAT (Hany et al., 2002). However, the detailed anatomy of human BAT had already been described as early as 1972 and a role of this tissue in diet-induced obesity proposed several years later (Heaton, 1972; Rothwell and Stock, 1979). The allometric comparison of BAT mass and norepinephrine induced thermogenesis capacity across multiple species predicts that mammals larger than $10 \mathrm{~kg}$ should have no or insignificant amounts of BAT thermogenesis (Heldmaier, 1971). Accordingly, an a priori thermogenic function to defend normothermia in the face of low ambient temperatures is questionable in man. Indeed, estimating the contribution of BAT to cold induced thermogenesis leads to a marginal to negligible fraction (Klingenspor and Fromme, 2012). However, the discovered amounts of BAT are sufficient to burn more than $4 \mathrm{~kg}$ of fat during 1 year and may thus very well be a component of organismic energy balance control (Virtanen et al., 2009). Moreover, the targeted pharmacological activation of brown fat energy dissipation is a promising strategy to combat the global obesity epidemic and its associated diseases, but requires understanding how exactly UCP1 structure enables its unique, regulated uncoupling property. 


\section{THERMOGENIC FUNCTION OF BAT}

While white adipose tissue stores energy in form of triglycerides, BAT is an energy-dissipating organ. Brown adipocytes contain a high number of mitochondria and these contain vast amounts of UCP1 totalling up to $5-8 \%$ of mitochondrial protein (Lin and Klingenberg, 1980). Usually the mitochondrial inner membrane is the place where final conversion of nutrient energy into ATP occurs. Combustion of lipids, carbohydrates and proteins results in the production of reduction equivalents, which feed electrons into the respiratory chain. Electrons are passed along a redox gradient until they finally reduce oxygen to water. The energy liberated by the redox reactions drives the export of protons from the matrix into the intermembrane space, creating a proton motive force across the membrane. The ATP synthase utilizes the energy conserved in the proton gradient and phosphorylates ADP to ATP.

In BAT this energy fixation can be interrupted and metabolization of substrates leads to a sustained direct conversion of nutrient energy to heat. Upon adrenergic stimulation lipases mobilize fat from lipid droplets and free fatty acids are rapidly metabolized. Due to the presence of UCP1 in the inner mitochondrial membrane this does not result in ATP production, as UCP1 shortcircuits the cycling of protons, which usually couples respiratory chain activity to ATP production (Figure 1). In non-stimulated conditions UCP1 is probably inhibited by purine nucleotides, but when activated by free fatty acids, catalyzes a proton flux into the mitochondrial matrix. Thus, the liberation of fatty acids upon cold stimulation fuels heat production dually, by serving as metabolic substrate and by directly activating UCP1.

\section{MOLECULAR ASPECTS OF UCP1 FUNCTION}

Despite intense research on UCP1 function several questions concerning its precise mechanism, which might affect its potential as therapeutic target, are unresolved. For example it is still disputed if UCP1 contributes to basal leak of BAT mitochondria, leaving the question if UCP1 would just have to be present or also activated to dissipate excess energy (Parker et al., 2009; Shabalina et al., 2010).

Regulators of UCP1 had been known even before the protein itself was purified and sequenced. Until today the interaction with the inhibitory nucleotides and especially the mechanism of activation by fatty acids is not finally understood. The nucleotide binding of UCP1 has been characterized by measuring GDP binding to wildtype and mutated versions of the protein in heterologous systems. This strategy identified an interacting region in the Cterminal part of the protein as well as individual amino acid residues distributed in the primary sequence providing charges for the interaction with purine nucleotides (Modriansky et al., 1997; Winkler et al., 1997; Echtay et al., 1998). According to the threedimensional model these residues position in close proximity to each other.

There are different models concerning the activation of UCP1 by fatty acids, being elaborations of two main hypotheses, one claiming that fatty acids are cofactors, needed to form the transport channel for the protons or to overcome nucleotide inhibition (Winkler and Klingenberg, 1994; Klingenberg and Huang, 1999; Shabalina et al., 2004), the other one stating that fatty acids are the substrate of transport. According to this model fatty acid anions would be transported to the intermembrane space by UCP1 and protonated fatty acids would flip-flop back into the matrix to complete proton translocation (Skulachev, 1991; Jezek et al., 1994; Garlid et al., 1998).

So far only one member of the mitochondrial anion transporter family, the ANT, has been crystallized. Three-dimensional models of UCP1 are calculated based on its sequence and the ANT structure, but of course might not reflect the actual situation in the membrane. ANT was crystallized as a monomer whereas almost since the beginning of UCP1 research it was assumed that it functions as a homodimer. This was based on GDP binding stoichiometry, sedimentation analyses, and cross-linking studies (Lin et al., 1980; Lin and Klingenberg, 1982). In a recent review all these findings were carefully reanalyzed, explaining why these results might have been obtained even though UCP1 in BAT mitochondria works as monomer, for example by artificial aggregation in detergents or overestimation of protein content in the presence of detergent (Kunji and Crichton, 2010). Knowing the structure of the wildtype protein or having the ability to compare it to mutant versions of the protein would greatly facilitate to clarify how UCP1 interacts with its known inhibitors and activators or to predict which novel substances might also be able to interact.

Knowledge about protein structure and interacting molecules might also help to learn more about the physiological function of UCP1. It has been shown that UCP1 can be activated by superoxide and reactive alkenals, supporting an involvement in the protection against reactive oxygen species (ROS) damage, according to the mild uncoupling theory (Skulachev, 1996). Functional analysis of isolated BAT mitochondria from wildtype and UCP1 knockout animals supports this theory, as under basal conditions mitochondria from wildtype animals produce less ROS than knockout animals, but reach the same level of ROS production when UCP1 is inhibited by addition of GDP (Oelkrug et al., 2010).

\section{UCP1 ORTHOLOGS AND PARALOGS}

Among the UCP1 orthologs rodent UCP1 is the best characterized uncoupling protein but studies of other UCP orthologs and paralogs will be instrumental to elucidate structure-functionrelationships. Comparison of the characteristics of uncoupling proteins from different species may reveal potentially crucial conserved residues or domains of which the functional relevance can be tested in targeted mutagenesis studies.

The paralogs UCP2 and UCP3 were discovered due to sequence similarity with UCP1, with 59\% for UCP2 and 57\% for UCP3 (Boss et al., 1997; Fleury et al., 1997; Gimeno et al., 1997). They differ in their tissue specific expression pattern, as UCP3 is expressed in skeletal muscle, heart and BAT, and UCP2 in multiple tissues, with an important role in immune cells and in beta cells (Pecqueur et al., 2001). For both paralogs no definite physiological function could be assigned as the respective knockout models do not display a clear phenotype (Brand and Esteves, 2005). UCP3 expression is elevated in physiological situations where free fatty acid levels in plasma are elevated. This led to the assumption that UCP3 plays a role in fatty acid metabolism. The fact that the UCP3 knockout mouse is not prone to 3,4-methylenedioxymethamphetamine (MDMA)-induced hyperthermia hinted toward an involvement in thermoregulation. There are several studies showing that UCP2 plays a role in beta cell function and affects glucose stimulated 
insulin secretion. Both UCP2 and UCP3, like UCP1, are supposed to protect the cell from excessive production of ROS according to the mild uncoupling theory (Skulachev, 1996). The regulation of the activity of UCP2 and UCP3 seems to differ from UCP1, as they are activated by superoxide and reactive alkenals but not by fatty acids alone. UCP1 orthologs for which uncoupling function has been analyzed, including carp UCP1 (Jastroch et al., 2007), elephant shrew UCP1 (Mzilikazi et al., 2007) and marsupial UCP1 (Polymeropoulos et al., 2011), can be used for comparisons of structure and function. It will be stressed in this review that valid comparisons require the use of suitable expression systems, as otherwise the proteins are characterized on a different mitochondrial background which might contribute to differences in function not related to protein structure. There are also several studies on BAT in larger mammals, like sheep and bovine, which are only exposed to thermal stress after birth and during early juvenile development but not in their adult life history. These studies mainly focus on the aspect of emergence and persistence of the tissue during the postnatal phase and juvenile development (Carstens, 1994; Symonds et al., 2011; Taga et al., 2011), rather than directly testing the function of the uncoupling protein.

\section{HUMAN BAT AND MOLECULAR ASPECTS OF HUMAN UCP1}

From a biomedical perspective it is certainly of capital importance to study the human UCP1 protein and its function. This may not be obvious on the first glance but, e.g., mouse and human UCP1 only share less than $80 \%$ identity on the amino acid level. The initial three reports of significant amounts of active human BAT in 2009 confirmed the presence of mRNA and protein of human UCP1 in human BAT by immunohistochemistry and quantitative PCR, respectively (Cypess et al., 2009; van Marken Lichtenbelt et al., 2009; Virtanen et al., 2009). These findings have since been reproduced multiple times (Saito et al., 2009; Zingaretti et al., 2009; Svensson et al., 2011). Earlier, human patients with pheochromocytoma have been studied, a neuroendocrine disease leading to excessive release of catecholamines and the appearance of BAT-like tissue depots in the body. Samples of this periadrenal, perirenal, and omental tissue express $\sim 30 \mu \mathrm{g}$ UCP1/mg mitochondrial protein, which is a concentration comparable to the expression in the interscapular BAT of mice acclimated to room temperature (Table 1; Lean et al., 1986a). Healthy control subjects, however, express only $\sim 3 \mu \mathrm{g} \mathrm{UCP} 1 / \mathrm{mg}$ mitochondrial protein in perirenal and axillary fat depots (Lean et al., 1986b). It is unclear whether this low concentration is due to a dilution of brown with white adipocyte mitochondria or indeed a far lower level of UCP1 expression in brown adipocytes. Furthermore, other human fat depots not studied so far may display very different UCP1 expression. Even less is known about human UCP1 on the level of functional or mechanistic studies and it remains elusive whether human UCP1 is similarly effective and tightly regulated as its wellstudied rodent counterparts. We would like to emphasize the need to remedy this deficit and in the following we systematically present test systems currently available for this challenging task.

\section{TEST SYSTEMS FOR UCP1 FUNCTION}

Several test systems have been applied in research on UCP1 function, such as proteoliposomes, yeast, and mammalian cells, including brown adipocytes. Initial studies depended on animal tissue as the sole source for UCP1. They were conducted with mitochondria isolated from animals after exposure to different treatments (cold exposure, high fat diet feeding, drug application) to alter UCP1 expression, or with UCP1 first purified from mitochondria and then reconstituted in proteoliposomes. Cloning and sequencing of UCP1 cDNA and protein (Aquila et al., 1985; Bouillaud et al., 1986) enabled the use of heterologous expression systems either as a source for the purified protein or as a source for mitochondria containing UCP1 at variable concentrations. With these systems it was possible to study the consequences of mutations inserted

Table 1 | Comparison of maximum UCP1-dependent $\mathrm{H}^{+}$transport rates in different test systems.

\begin{tabular}{|c|c|c|c|c|c|c|}
\hline System & UCP1 & $\begin{array}{l}\text { Mitoprotein } \\
(\mu \mathrm{g} / \mathrm{mg})\end{array}$ & $\mathbf{m V}$ & $\begin{array}{l}\mathrm{nmol} \mathrm{H}^{+*} \min ^{-1 *} \mu \mathrm{g} \\
\mathrm{UCP}^{-1} * \mathrm{mV}^{-1}\end{array}$ & $\mathrm{H}^{+*} \mathrm{~s}^{-1}$ & Reference \\
\hline \multirow[t]{5}{*}{ BAT mitochondria } & Hamster (cold) & 54 & 180 & 0.05 & 5.0 & Rial et al. (1983) \\
\hline & Mouse (RT) & 29.8 & 141 & 0.02 & 1.7 & Monemdjou et al. (1999) \\
\hline & Rat (RT) & 13 & 143 & 0.56 & 44.0 & Esteves et al. (2006) \\
\hline & Mouse (RT) & 29.8 & 147 & 0.34 & 27.5 & Shabalina et al. (2006) \\
\hline & Mouse (RT) & 29.8 & 147 & 0.31 & 24.8 & Parker et al. (2009) \\
\hline \multirow[t]{3}{*}{ Liposomes } & Rat expressed in yeast & & & & 1.2 & Murdza-Inglis et al. (1991) \\
\hline & Hamster expressed in yeast & & & & 55.0 & Echtay et al. (1998) \\
\hline & Rat expressed in E. coli & & & & 11.0 & Jaburek and Garlid (2003) \\
\hline Lipid bilayer & Hamster & & 180 & 0.14 & 14.0 & Urbankova et al. (2003) \\
\hline Yeast mitochondria & Mouse & 0.9 & 138 & 9.28 & 704.0 & Stuart et al. (2001) \\
\hline HEK UCP1 mitochondria & Mouse & 4.8 & 155 & 0.88 & 74.8 & Unpublished data \\
\hline Brown fat cell mitochondria & Mouse & 2.8 & 141 & 1.17 & 90.8 & Unpublished data \\
\hline
\end{tabular}

Values were extracted from tables and figures of publications and UCP1-dependent transport rates were calculated by subtracting respiration of mitochondria from

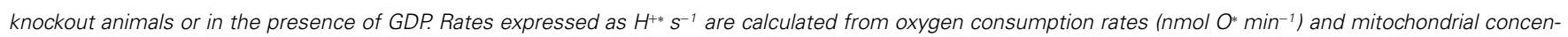

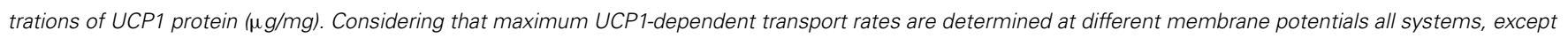
yeast, for which an uncoupling artifact has been published, are in a comparable range. 
into the protein and to compare the properties of UCP orthologs and paralogs. Since UCP1 knockout animals have been generated (Enerback et al., 1997), comparison of the bioenergetic properties of normal and UCP1-ablated brown fat mitochondria are another valuable system to study UCP1 function.

In the following we will briefly introduce the principle of different test systems and their most frequent applications and discuss their strengths and weaknesses (Table 2). Major insight gained with these test systems concerning the structure-functionrelationship of UCP1 will be highlighted. Moreover, we provide a comprehensive summary on which aspects of human UCP1 have been studied so far using these test systems.

\section{PROTEOLIPOSOMES}

Liposomes are a standard tool to study the transport function of membrane proteins. The protein(s) of interest are reconstituted into the bilayer phospholipid membrane of vesicles with a diameter of 5-15 nm enclosing an aqueous compartment. This membrane mimics the natural phospholipid environment, provides a lipophilic compartment for protein solubilization and facilitates proper folding. Purified native proteins or recombinantly expressed proteins can be inserted into this membrane by mixing the components in the presence of detergent. Transport characteristics of the inserted membrane protein can be studied by loading the vesicles with specific buffers. Differential buffer composition in- and outside of the vesicle generates the driving force for subsequent experiments where ion flux is measured. The initial study reconstituting UCP1 in this system was published in 1983 (Bouillaud et al., 1983) followed by the demonstration of $\mathrm{H}^{+}$transport by UCP1 in proteoliposomes two years later (Klingenberg and Winkler, 1985). The first successful reconstitution of recombinant UCP1 from $E$. coli inclusion bodies was performed by Jaburek and Garlid (2003), who could measure $\mathrm{H}^{+}$transport rates comparable to the reconstituted native UCP1 isolated from hamster BAT.

Ion transport is usually detected by dyes, which are quenched by a specific ion or which aggregate when proteoliposomes are polarized. Therefore results are presented as relative transport rates above basal or absolute ion transport rates per time and mg reconstituted protein (Figure 2 ).

The main advantage of the proteoliposome system is that UCP mutants as well as paralogs and orthologs can be directly compared in an identical environment in the absence of secondary influences on UCP function by other mitochondrial or cellular processes. Variation due to different intactness of isolated mitochondria can be excluded and furthermore effects of membrane composition can easily be tested.

A major disadvantage is the inconsistency of results for proteoliposome studies coming from different labs. Variables like protein source (native, recombinant from yeast mitochondria or $E$. coli inclusion bodies), isolation and purification protocol (detergents, purification columns, dialysis steps), and reconstitution conditions (membrane composition, removal of detergent) contribute to highly divergent results concerning various aspects of uncoupling protein function. For example, estimations of correct UCP orientation in vesicles vary between 50 and $85 \%$ and transport rates in the range of $1.2-55 \mathrm{H}^{+*} \mathrm{~s}^{-1}$ have been reported
(Murdza-Inglis et al., 1991; Echtay et al., 1998) (Table 1). Direct comparison with native protein in the same setting seems to be the most feasible approach to evaluate if appropriate experimental conditions have been chosen. Otherwise, incorrect folding or protein aggregation will not be recognized and lead to overor underestimation of transport activities. A further disadvantage is that transport is analyzed at low driving force. This is a major drawback as the regulation of UCP1 is strongly dependent on membrane potential and shows strong increases in fatty acid induced uncoupling at high driving forces.

Several important findings were achieved by the use of UCP1 proteoliposomes. It was demonstrated that UCP1 is indeed capable of catalyzing a net proton flux and transport rates measured argue for a carrier characteristic (Klingenberg and Winkler, 1985). Furthermore, UCP1 molecules were cross-linked in the isolated state, in mitochondria, and after reconstitution into liposomes and in the liposome system it was shown that forced dimerization does not impair activity, as two cross-linked molecules still bind GDP and still display $\mathrm{H}^{+}$transport (Klingenberg and Appel, 1989). Studies with fatty acids and modified analogs or crosslinking of analogs to UCP1 set out to clarify whether fatty acids are essential cofactors or if fatty acid anions are the substrate of transport (Garlid et al., 1996; Jezek et al., 1996; Breen et al., 2006). This question still has not been finally resolved. Liposomes were also suggested to be a suitable test system for large scale screening of molecules to identify novel regulators of UCP1 function (Mozo et al., 2006).

Human UCP1 has been expressed in E. coli inclusion bodies and reconstituted for circular dichroism spectroscopy in solution and in liposomes (Ivanova et al., 2010). Remarkably there are no published functional studies in liposomes using the human UCP1, although there are several studies comparing human UCP2 and human UCP3 with rodent UCP1. It seems that the obsolete assumption of BAT disappearance shortly after birth in humans has constrained investigations with the human protein.

\section{PLANAR LIPID BILAYERS}

Proteoliposomes spontaneously form a monolayer at the surface of the suspension (Schindler, 1979). Planar lipid bilayers can be formed by the combination of two such monolayers and then have a capacity and dielectrical thickness which is comparable to biological membranes (Montal and Mueller, 1972). The conductance of proteins integrated in these membranes can be analyzed by recording the conductivity of the membrane with a patch clamp amplifier. The first analysis of uncoupling proteins in this system reconstituted purified hamster UCP1 and was performed in 2003 (Urbankova et al., 2003).

The activity of uncoupling proteins in a lipid bilayer membrane is described in current voltage plots which can be used to calculate transported molecules per molecule of the analyzed protein.

Planar lipid bilayer membranes have similar advantages like proteoliposomes, as they allow comparison of different UCPs in a defined background, which can be varied, with respect to membrane phospholipid composition, fatty acids or other protein components. Furthermore, this system allows characterization of the proteins over a broad range of voltages, as the driving force is not applied by buffer loading, but by a voltage source. 
As in proteoliposomes the correct folding, insertion, and orientation of purified, native or recombinant proteins into the membrane is critical in this test system. The possibility that cofactors are missing or artifactual transport is detected can hardly be excluded.

With the planar lipid bilayer test system the transport rate of UCP1 isolated from hamster BAT was $14 \mathrm{H}^{+*} \mathrm{~s}^{-1}$ (Urbankova et al., 2003; Table 1). It was shown that fatty acids are obligatory cofactors for UCP1 function and that the activation by fatty acids is membrane potential dependent (Rupprecht et al., 2010). Concerning the debate on the transport mechanism by UCP1, experimental results from this system argue for facilitated flip-flop/transport of deprotonated fatty acids to the intermembrane space. Lipid containing bilayer membranes already display a certain proton conductance, which is dependent on the potential above the membrane. The co-incorporation of uncoupling proteins amplifies this conductance but does not change the membrane potential dependent kinetics (Rupprecht et al., 2010).

Notably the function of human UCP1 has also been analyzed in the planar lipid bilayer system by purification and reconstitution from E. coli inclusion bodies. Transport activity of human UCP1 was qualitatively similar to UCP1 isolated from Syrian hamster BAT (Beck et al., 2006). Furthermore it was shown that polyunsaturated fatty acids activate human UCP1 and UCP2 in planar lipid bilayers (Beck et al., 2007).

\section{YEAST}

Yeast as a prototypic eukaryotic model organism is easily accessible to genomic modifications. The yeast genome does not contain a UCP1 ortholog, which is a clear advantage for functional studies. Like E. coli it can serve for recombinant overexpression of membrane proteins as the starting material for functional studies in proteoliposomes and planar lipid bilayers. Garlid and colleagues, making use of the yeast system to ectopically express UCP1, demonstrated that the protein isolated from yeast and reconstituted into proteoliposomes exhibited characteristics similar to the native UCP1 isolated from BAT (Murdza-Inglis et al., 1991). This opened up new opportunities for mutation studies, giving first insights into structure-function-relationships.

Besides serving for recombinant protein production intact cells or isolated mitochondria from yeast expressing different UCPs can be analyzed to identify consequences of UCP activity for growth, cellular respiration or change of membrane potential as monitored by fluorescent dyes.

Compared to the E. coli expression system yeast overcomes the problem of purification and reconstitution of membrane proteins from inclusion bodies because it is a eukaryotic cell, where heterologously expressed uncoupling proteins are inserted into mitochondria, their native environment. Yeast can still be grown easily in large scale, allowing the production of sufficient amounts of UCPs for analyses, with stable conditions. Various yeast strains with deficiencies in possible cofactors are available and can be used to test whether UCP1 function is affected in mitochondria of such a strain. Studies on coenzyme Q deficient strains, for example, demonstrated that coenzyme $Q$ is not a necessary cofactor for uncoupling proteins (Esteves et al., 2004), thus supporting previous findings in proteoliposomes (Jaburek and Garlid, 2003). Yeast has been used for a proteomic study, where the mitochondrial proteome of yeast heterologously expressing UCP1 was compared to that of wildtype yeast (Douette et al., 2006). UCP1 expression leads to a slight increase in mitochondrial mass and upregulation of proteins that help to maintain ATP levels despite uncoupling activity.

Although being a eukaryotic cell, yeast is a single cell organism which precludes analysis of physiological functions of UCP1. Furthermore, Stuart et al. (2001) demonstrated that expression of UCP1 above $1 \mu \mathrm{g} / \mathrm{mg}$ leads to an uncoupling artifact in isolated mitochondria, probably due to improper folding or insertion of the protein in the inner mitochondrial membrane. At a concentration of $\sim 30 \mu \mathrm{g} / \mathrm{mg}$ UCP1 in brown fat mitochondria of mice kept at room temperature exhibits a transport activity of $\sim 25 \mathrm{H}^{+*} \mathrm{~s}^{-1}$, whereas in yeast even without artifactual uncoupling the activity was $\sim 700 \mathrm{H}^{+*} \mathrm{~s}^{-1}$ (Table $\mathbf{1}$ ).

Most of the structure-function studies on UCP1 have been conducted in yeast. Mutated versions of UCP1 were expressed and either characterized after reconstitution in liposomes or in isolated yeast mitochondria. Of special interest is one study, where protein domains were swapped between UCP1 and UCP3. Hagen and Lowell (2000) demonstrated that the second part of the tripartite structure of UCP1 is necessary and sufficient for activation by fatty acids, which was analyzed further by Jimenez-Jimenez and colleagues. They demonstrated that it is the central matrix loop of UCP1 which is required for fatty acid sensitivity. Exchange of this part of the sequence with the corresponding UCP2 sequence resulted in loss of fatty acid sensitivity (Jimenez-Jimenez et al., 2006).

So far yeast has not been employed as a model organism to study human UCP1 structure and function.

\section{MAMMALIAN CELL LINES}

Shortly after the availability of the UCP1 sequence in 1985 the establishment of mammalian test systems was attempted, suitable for the expression of different UCP variants to analyze structurefunction-relationships. Chinese hamster ovary $(\mathrm{CHO})$ cells were stably transfected with rat UCP1. The assessment of rat UCP1 function in isolated mitochondria from these cells revealed that they were slightly uncoupled, and respiratory control was regained by addition of $1 \mathrm{mM}$ GDP. This treatment also partially restored membrane potential, but as it did not reach the level of mitochondria from control cells, an uncoupling artifact as published for yeast could not be excluded (Casteilla et al., 1990; Stuart et al., 2001). A further limitation was that the expression level of rat UCP1 in these mitochondria was around $1 \mu \mathrm{g} / \mathrm{mg}$ protein and thus much lower than in BAT mitochondria (Table 1). Transient overexpression of UCP1 in HepG2 liver cells led to a decrease in ATP production, but the authors did not try to quantify catalytic activity (Gonzalez-Muniesa et al., 2005). Ectopic overexpression of mouse UCP1 in a fibroblast cell line was applied to characterize in detail the effect on cellular metabolism. The authors found that 3T3L1 cells expressing UCP1 accumulate less lipid due to reduced lipid synthesis, while oxygen consumption is only marginally stimulated. Beta-oxidation and several differentiation markers are not affected, indicating that UCP1 expression in white adipose tissue might provide an approach to reduce lipid accumulation (Si 


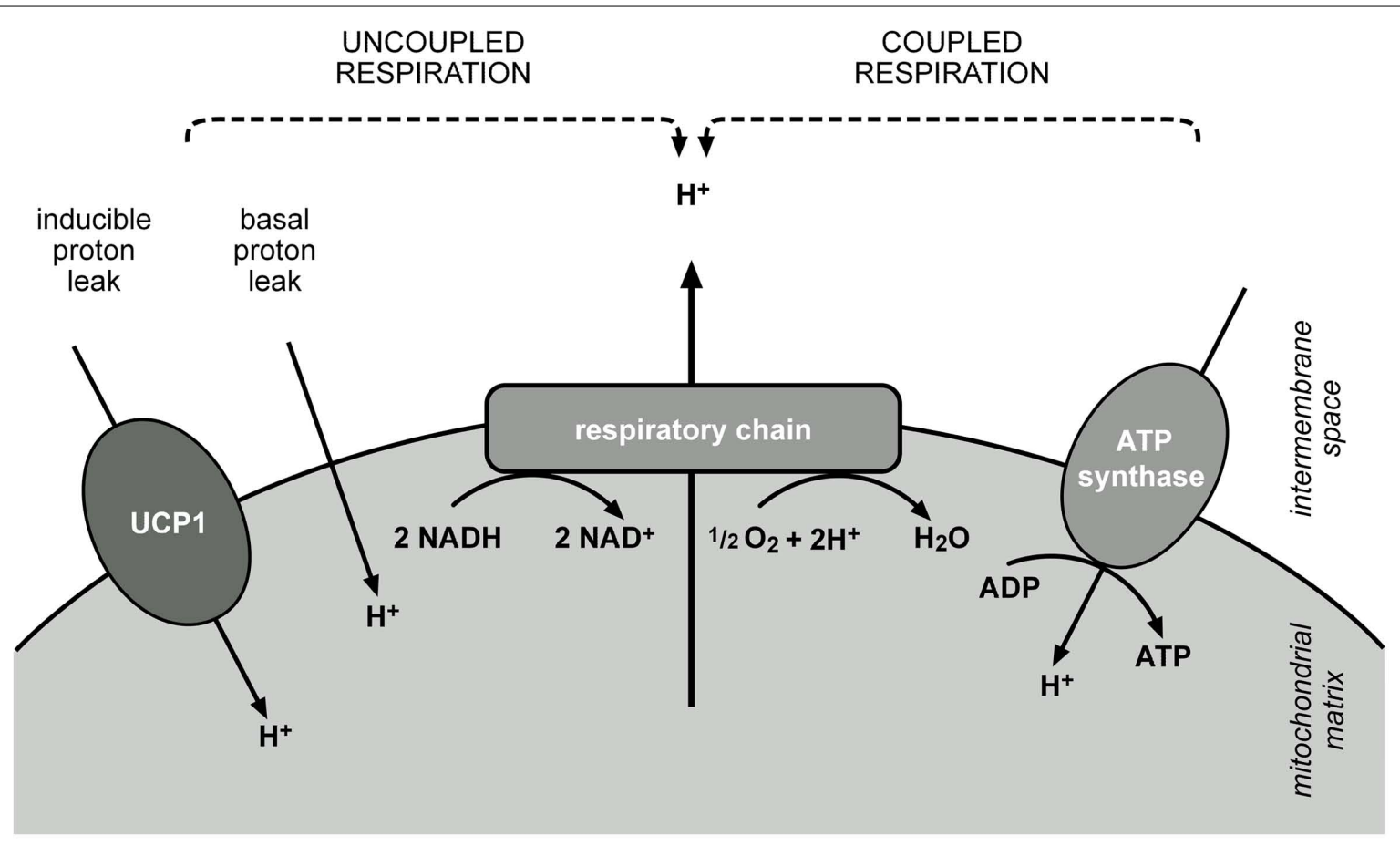

FIGURE 1 | Dissipation of energy from nutrient combustion at the mitochondrial inner membrane. Reduction equivalents feed electrons into the respiratory chain, which are passed along a redox gradient and reduce oxygen to water. Energy released by these reactions is stored as a proton gradient across the membrane, as protons are pumped into the intermembrane space. ATP synthase utilizes this energy and the flux of protons along the enzyme leads to the phosphorylation of ADP to ATP.
Activity of the respiratory chain and ATP synthase are coupled by the proton gradient (coupled respiration). Coupling can be reduced by a basal leak of protons across the membrane, present in every cell, or by an inducible proton leak, catalyzed by specific proteins, in case of BAT mitochondria mainly by UCP1 (uncoupled respiration). Proton translocation by leak pathways prevents fixation of energy and releases it as heat. et al., 2007). In another study, human UCP1 was expressed in INS1E cells, reaching expression levels of $1-1.5 \mu \mathrm{g} / \mathrm{mg}$ mitochondrial protein. UCP1 activity could be induced by addition of fatty acids, leading to an increased respiration and lower membrane potential (Galetti et al., 2009), whereas heterologous expression of human UCP2 in the same system did not affect mitochondrial bioenergetics.

Determination of UCP1 activity in mammalian mitochondria is often performed by the analysis of cellular or mitochondrial respiration but this gives just a rough impression of the coupling state. Only when membrane potential is determined at the same time it is possible to describe proton leak or even proton leak kinetics, as the need for respiratory activity depends largely on the membrane potential which has to be maintained. If two mitochondrial preparations both consume a certain amount of oxygen under non-phosphorylating conditions, those defending a higher membrane potential are more coupled, a fact you would miss by only looking at respiration. Respiration is mostly measured with Clark-type electrodes while membrane potential can be determined with fluorescent dyes or electrodes which detect distribution of lipophilic cations, e.g., TPMP ${ }^{+}$(Brand, 1995). Several steady states of membrane potential and oxygen consumption can be titrated and plotted against each other, resulting in a curve describing proton leak kinetics (Figure 3). Two curves can be compared by regarding oxygen consumption (respiratory activity) needed to maintain a certain membrane potential.

The obvious advantage of mammalian cell systems is that they represent the natural background on which the probability of proper folding and insertion into the membrane is higher than in other systems, even if UCP1 is expressed in a non-brown fat cell. In our laboratory we have generated a novel mammalian UCP1 expression model by stable transfection of HEK293 cells with an expression vector carrying the mouse UCP1 cDNA under control of the CMV promoter. As exemplified in proton leak measurements UCP1 in isolated mitochondria from these cells is activated by the addition of palmitate (Figure 3A). Maximum transport activity of mUCP1 was $\sim 75 \mathrm{H}^{+} \mathrm{s}^{-1}$ (Table 1). In the presence of GDP this activation is diminished and at $1 \mathrm{mM}$ GDP the proton leak of mitochondria expressing UCP1 at a level of $4.8 \mu \mathrm{g} / \mathrm{mg}$ mitochondrial protein is identical to the proton leak of mitochondria from normal HEK293 cells. This demonstrates that stable expression of UCP1 in these cells at the given expression level does not cause any uncoupling artifact.

Nevertheless, one has to keep in mind that heterologous overexpression may induce stress in a cell which may indirectly impact mitochondrial function. Furthermore, immortalized cell culture models usually develop altered cell physiology during the immortalization process which may for example switch their metabolism 


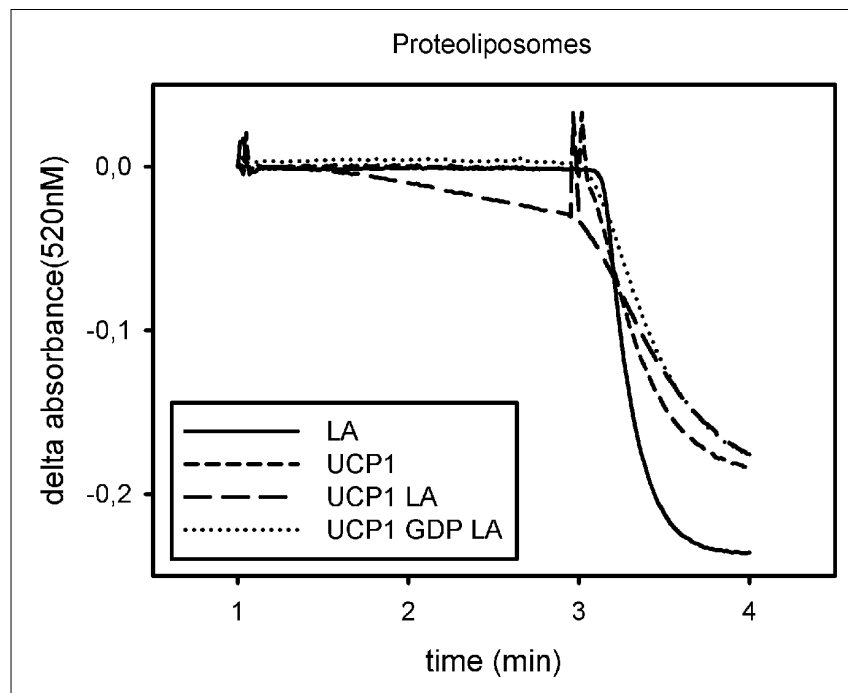

FIGURE 2 | Exemplary trace for analysis of UCP1 function in proteoliposomes. Absorbance of safranin $\mathrm{O}$ is plotted against time. Addition of nigericin at minute 1 induces polarization of the liposomes, measured as a decrease in safranin $\mathrm{O}$ absorbance, if a proton translocating pathway is present in the vesicles. Addition of CCCP at minute 3 leads to complete polarization and indicates vesicle volume. The initial slope after addition of nigericin is a measure for the proton translocation pathway, if there is one present and active. UCP1 is not active under basal conditions (UCP1) but mediates proton transport in the presence of lauric acid (LA).

This can be prevented by addition of GDP (GDP LA). Addition of lauric acid to vesicles not containing UCP1 does not induce proton translocation (LA)

toward glycolysis, as indicated by elevated lactate production, e.g., in the CHO expression system (Casteilla et al., 1990).

So far no one has tested the function of human UCP1 in a heterologous mammalian expression system. Given the many advantages of this easy to manipulate system, future studies will certainly remedy this surprising deficit.

\section{BROWN ADIPOCYTE CELL LINES}

Stable brown preadipocyte cell lines have been generated by several different strategies. A first one is isolation, serial passage, and selection of stromal vascular fraction (SVF) cells either from BAT of wildtype mice (Forest et al., 1987) or from BAT hibernoma of transgenic mice with adipose-specific expression of SV40 fragments (Ross et al., 1992). A second strategy has been the cultivation and SV40 immortalization of the SVF from BAT depots of individual mouse embryos or newly born mice (Benito et al., 1993; Klein et al., 1999). These cell lines are maintained as precursor cells, but in response to hormonal stimulation differentiate into brown adipocytes. Therefore they do not only allow analysis of UCP1 function but can also be used to study differentiation of brown adipocytes and regulation of UCP1 expression. The UCP1 expression level in these cells is often low and requires induction by activators of UCP1 transcription for functional analyses.

Studying brown adipocyte cell lines allows analysis in a native background with lower variation than in tissue. In cell culture, molecular biology tools allow overexpression and

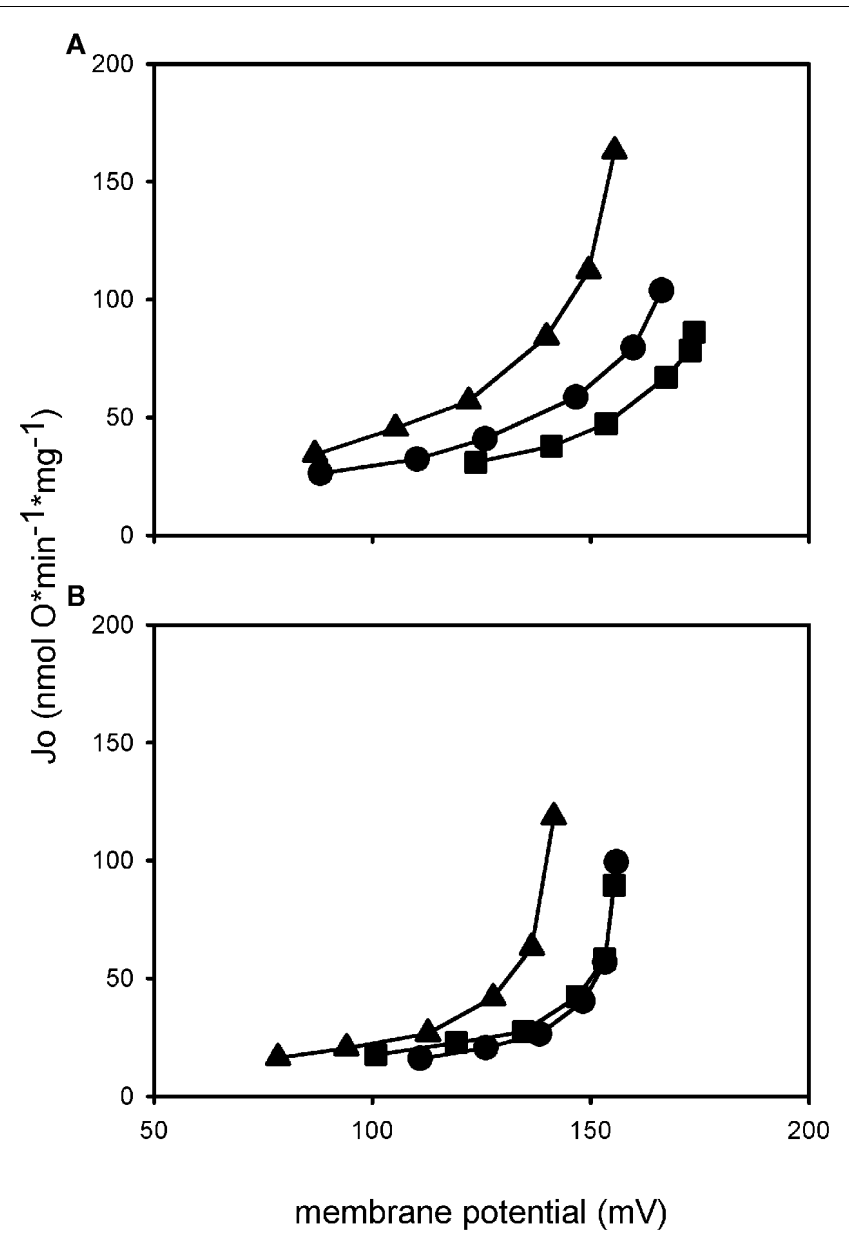

FIGURE 3 | Proton leak kinetics of isolated mitochondria. Mitochondria from HEK UCP1 cells (A) and mitochondria from a differentiated brown preadipocyte cell line (B). Addition of palmitate (triangle) in both systems leads to an increase in proton leak compared to basal conditions (circle), indicated by the upwards shift of the curve. Coincubation with GDP (square) prevents the activation by palmitate, demonstrating that it is mediated by UCP1. Proton conductance of HEK UCP1 mitochondria in the presence of GDP is lower than under basal conditions, whereas mitochondria from brown adipocytes are coupled back to basal level.

knockdown of specific factors to test their relevance as cofactors of UCP1 function. A brown adipocyte model can be expected to endogenously feature all interaction partners necessary for optimal UCP1 function, all signaling cascades leading to its activation and comparable metabolic characteristics, substrate specificity, and preference. The possibility to immortalize cells from BAT SVF of individual mice implicates that also transgenic mice can be analyzed, even from models with perinatal mortality. This allows the generation of cell lines carrying knockout/knockin alleles, which had been immensely challenging in the past.

A disadvantage of all cell culture lines is that they change with increasing passage number, somehow limiting the advantage of stability. Low levels of UCP1 expression and the necessity to treat cells with inducing substances further increases variability. 
A recent important finding in cultured brown adipocytes does not concern uncoupling protein function but developmental origin of the cells. It was shown that brown adipocytes and muscle cells originate from the same progenitor, being determined to differentiate into muscle or adipocyte by the absence or presence of PRDM16 (Seale et al., 2007). This finding implies that brown and white fat cells are less related than brown fat and muscle, and underlines the energy-dissipating function of BAT in contrast to the energy conserving function of WAT. Studies in different cell lines have demonstrated the importance of T3, insulin and $\beta$-adrenergic signals for brown fat differentiation, but also for retinoids and PPARy (Klaus et al., 1994, 1995; Alvarez et al., 2000; Nedergaard et al., 2005). Even commonly used white adipocyte cell models, mouse embryonic fibroblasts (MEF), can be induced to express UCP1 by treatment with retinoic acid (Mercader et al., 2010).

In our laboratory we have recently started to evaluate UCP1 function in mitochondria isolated from an immortalized brown preadipocyte cell line (kindly provided by B. Spiegelman; Uldry et al., 2006). After differentiation and treatment with isoproterenol and retinal these cells express approximately $2.8 \mu \mathrm{g} U \mathrm{UCP} 1 / \mathrm{mg}$ mitochondrial protein. The proton conductance of isolated mitochondria can be increased by the addition of palmitate and this can be prevented by the addition of $1 \mathrm{mM}$ GDP indicating uncoupling protein function (Figure 3B). Maximum fatty acid induced UCP1 activity was $\sim 90 \mathrm{H}^{+*} \mathrm{~s}^{-1}$, which is in the same range as maximum UCP1 activity in HEK cells stably expressing UCP1 (Table 1).

In 1997, a human brown preadipocyte cell line was generated from infant BAT tissue (Zilberfarb et al., 1997). UCP1 was detected by qPCR and Northern Blot but not further characterized on the functional level, due to low expression level. Very recently a study on precursor cells from human adipose tissue has been published (Lee et al., 2011). With the requirement of long culture times fibroblastic cells can be obtained from the SVF of supraclavicular fat depots, which then can be differentiated and do contain UCP1. No functional studies on human UCP1 have been conducted in these cell lines.

\section{BROWN ADIPOSE TISSUE MITOCHONDRIA FROM WILDTYPE AND MUTANT MICE}

One of the first and still widely used approaches to characterize UCP1 is to measure its function and impact on proton leak in isolated BAT mitochondria. Isolation of mitochondria makes them accessible to inhibitory or activating substances which might not pass the cell membrane. Furthermore it is possible to control substrate supply and to monitor membrane potential and respiration without having to correct for cell membrane potential or non-mitochondrial oxygen consumption in the cell. Isolated mitochondria were used for the identification of UCP1 and description of its fundamental characteristics even before it was purified or its sequence was available. Nucleotide binding of UCP1 was characterized, demonstrating $\mathrm{pH}$ sensitivity and a higher affinity to GDP and GTP compared to ADP and ATP (Rial et al., 1983; Huang and Klingenberg, 1995). Studies with isolated mitochondria also elucidated structural aspects of
UCP1. Tryptic digestion of UCP1 in isolated mitochondria, submitochondrial particles, and proteoliposomes revealed that the C-terminus of the protein is located in the intermembrane space (Eckerskorn and Klingenberg, 1987). Most commonly, mice, rats, hamsters, and guinea pigs have been employed in studies with isolated mitochondria. Comparison of BAT mitochondria from animals exposed to different conditions, e.g., cold adapted and kept at thermoneutrality, allowed to assess the effect of different UCP1 amounts. Analysis of mitochondria from wildtype and knockout mice allows clear assignment of mitochondrial characteristics to the presence and function of UCP1. The creation of transgenic mice even permits analysis of UCP1 function in mitochondria of tissues other than BAT. Ectopically expressed UCP1 in skeletal muscle mitochondria can be fully inhibited with GDP and activated with fatty acids. Furthermore UCP1 seems to be active in the resting state, as superoxide production is lower but reaches control levels when GDP is added (Keipert et al., 2010).

First studies assaying brown fat mitochondria mainly monitored activity of UCP1 by swelling experiments (Nicholls and Lindberg, 1973). Later measurements of respiration and membrane potential were applied to characterize proton leak kinetics, as described above. New technologies now facilitate studies of mitochondrial bioenergetics offering respirometry devices with either high-resolution (OROBOROS Instruments) or multiwell analysis of oxygen consumption and extracellular acidification rates (SEAHORSE BioSciences).

Given that BAT mitochondria are the native environment of UCP1 the protein is correctly folded and assembled in this test system. All necessary cofactors are present and the mitochondrium is equipped to sustain high respiratory activity, enabling maximum UCP1 activity.

In order to make use of these advantages the conditions for mitochondrial isolation must be chosen adequately. Isolation can damage mitochondria, most likely during homogenization of the tissue or by inadequate buffer conditions. It was found, that only in sufficiently low osmotic medium mitochondrial matrix volume expands and allows proper usage of $\mathrm{NAD}^{+}$linked substrates (Nicholls and Lindberg, 1972). Effects mediated by other carriers present in the mitochondrial inner membrane have to be excluded by proper controls. Mitochondria come directly from animals which introduces variation due to different life history of different animals. Body weight, exact housing temperature, and age are factors which have impact on mitochondrial characteristics and thus have to be carefully controlled (Porter and Brand, 1993; Harper et al., 1998).

A recent discussion which was based on studies in isolated mitochondria from wildtype and UCP1 knockout mice concerned a possible contribution of UCP1 to basal proton conductance in BAT mitochondria. Parker et al. (2009) found that basal, GDP-insensitive proton leak is higher in BAT mitochondria from wildtype mice compared to UCP1 knockout mice. Shabalina et al. (2010) argued that this is not due to a contribution of UCP1 to basal proton leak, but due to the assay buffer conditions, which selectively harm mitochondria from knockout animals. 
Table 2 | Advantages and disadvantages of different UCP1 test systems.

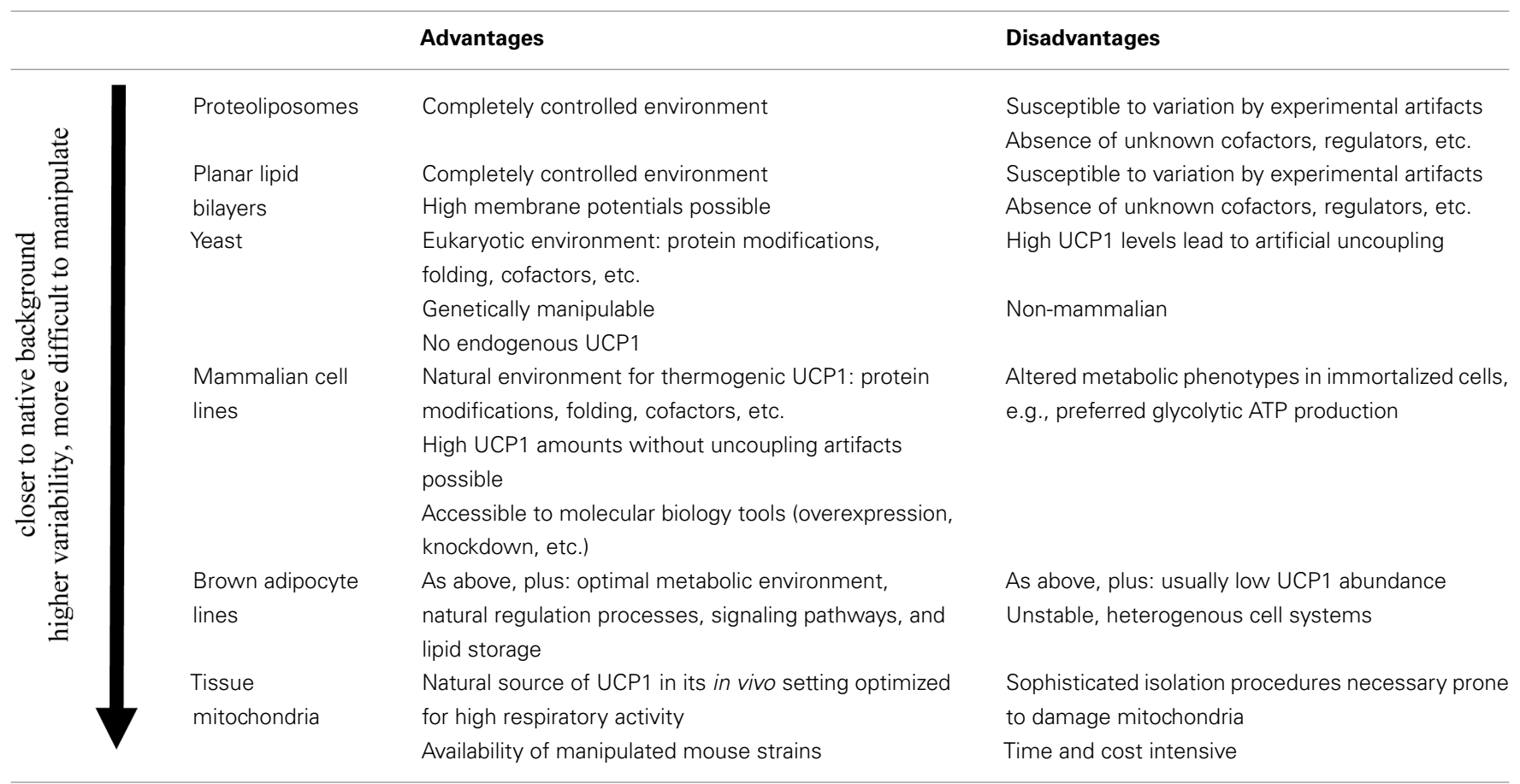

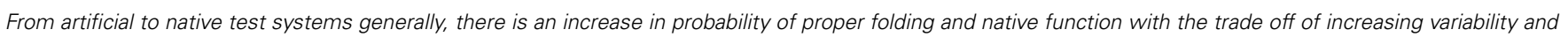

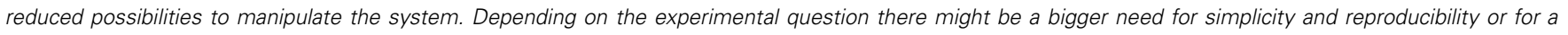
physiological background, and therefore in each case another test system the best choice.

So far there are no studies analyzing human UCP1 in BAT mitochondria, neither in human mitochondria nor after transgenic expression in animal mitochondria.

\section{CONCLUSION AND PERSPECTIVES}

The discovery of significant amounts of active BAT in humans has renewed interest in this organ and particularly in UCP1 as a pharmacological target to treat metabolic disease. Unfortunately, very little is known about the physiology of human BAT and most of our supposed knowledge is actually transferred from the study of rodents and other animals. This caveat applies to all aspects of BAT function including neuronal and hormonal regulation, recruitment of tissue hypertrophy and hyperplasia, heat production capacity and the cellular architecture like mitochondrial density and lipid droplet composition. It is equally true for the central question we focus on in this review, the structure and function of UCP1.

We have to keep in mind that the human UCP1 protein only shares less than $80 \%$ identity with rodent UCP1. Together with the protein sequences of all eutherian species it forms a group that is markedly different from UCP1 sequences of marsupials or other lower vertebrates (Hughes et al., 2009). It is assumed that this large phylogenetic gap between the eutherian and lower groups represents the acquirement of a regulated, thermogenic function of UCP1, arguing for this very role of human UCP1. On the other hand, as judged by allometric comparison of animals with different masses, a species as large as man should feature only negligible amounts of BAT, relieving selection pressure on efficient uncoupling by UCP1 (Heldmaier, 1971). Such a phenomenon can be observed, for instance, in all species of pigs. Being of the same size as man they have entirely lost an intact UCP1 gene (Berg et al., 2006). Sheep and bovine, however, have retained their UCP1 genes and exhibit functional BAT at least during the postnatal phase.

Activity and regulation of UCP1 proteins of different species have been measured (Table 1). Unfortunately, due to the large variation between methods and laboratories it is impossible to dissect the contribution of a species specific difference. It is thus essential to compare UCP1 from different species and including human UCP1 in one test system which does not display artifactual uncoupling due to UCP1 expression and in an experimental setup with low inter-experimental variability (Table 2). This will enable us to assess how easily our knowledge on UCP1 function can be transferred to human BAT and provide the groundwork for the search of compounds altering this function.

\section{ACKNOWLEDGMENTS}

The proteoliposome measurements (Figure 2) were performed in the laboratory of Dr. Bruno Miroux (Université Paris V, Institut de Biologie Physico-Chimique). We are grateful to Dr. Miroux for the fruitful discussions and thank Sandrine Masscheleyn for technical assistance. Verena Hirschberg was a member of the DFG Graduate School 1216. The chair for Molecular Nutritional Medicine is supported by the Else Kröner-Fresenius Zentrum Foundation. 


\section{REFERENCES}

Alvarez, R., Checa, M., Brun, S., Vinas, O., Mampel, T., Iglesias, R., Giralt, M., and Villarroya, F. (2000). Both retinoic-acid-receptor- and retinoid-X-receptor-dependent signalling pathways mediate the induction of the brown-adiposetissue-uncoupling-protein-1 gene by retinoids. Biochem. J. 345(Pt 1), 91-97.

Aquila, H., Link, T. A., and Klingenberg, M. (1985). The uncoupling protein from brown fat mitochondria is related to the mitochondrial ADP/ATP carrier. Analysis of sequence homologies and of folding of the protein in the membrane. EMBO J. 4, 2369-2376.

Beck, V., Jaburek, M., Breen, E. P., Porter, R. K., Jezek, P., and Pohl, E. E. (2006). A new automated technique for the reconstitution of hydrophobic proteins into planar bilayer membranes. Studies of human recombinant uncoupling protein 1. Biochim. Biophys. Acta 1757, 474-479.

Beck, V., Jaburek, M., Demina, T., Rupprecht, A., Porter, R. K., Jezek, P., and Pohl, E. E. (2007). Polyunsaturated fatty acids activate human uncoupling proteins 1 and 2 in planar lipid bilayers. FASEB J. 21, 1137-1144.

Benito, M., Porras, A., and Santos, E. (1993). Establishment of permanent brown adipocyte cell lines achieved by transfection with SV40 large T antigen and ras genes. Exp. Cell Res. 209, 248-254.

Berg, F., Gustafson, U., and Andersson, L. (2006). The uncoupling protein 1 gene (UCP1) is disrupted in the pig lineage: a genetic explanation for poor thermoregulation in piglets. PLoS Genet. 2, e129. doi:10.1371/journal.pgen.0020129

Boss, O., Samec, S., Paoloni-Giacobino, A., Rossier, C., Dulloo, A., Seydoux, J., Muzzin, P., and Giacobino, J. P. (1997). Uncoupling protein-3: a new member of the mitochondrial carrier family with tissue-specific expression. FEBS Lett. 408, 39-42.

Bouillaud, F., Ricquier, D., GulikKrzywicki, T., and Gary-Bobo, C. M. (1983). The possible proton translocating activity of the mitochondrial uncoupling protein of brown adipose tissue. Reconstitution studies in liposomes. FEBS Lett. 164, 272-276.

Bouillaud, F., Weissenbach, J., and Ricquier, D. (1986). Complete cDNAderived amino acid sequence of rat brown fat uncoupling protein. J. Biol. Chem. 261, 1487-1490.

Brand, M. D. (1995). "Measurement of mitochondrial protonmotive force," in Bioenergetics. A Practical
Approach, eds G. C. Brown and C. E. Cooper (Oxford: IRL Press), 39-62.

Brand, M. D., and Esteves, T. C. (2005). Physiological functions of the mitochondrial uncoupling proteins UCP2 and UCP3. Cell Metab. 2, 85-93.

Breen, E. P., Gouin, S. G., Murphy, A. F., Haines, L. R., Jackson, A. M., Pearson, T. W., Murphy, P. V., and Porter, R. K. (2006). On the mechanism of mitochondrial uncoupling protein 1 function. J. Biol. Chem. 281, 2114-2119.

Carstens, G. E. (1994). Cold thermoregulation in the newborn calf. Vet. Clin. North Am. Food Anim. Pract. 10, 69-106.

Casteilla, L., Blondel, O., Klaus, S., Raimbault, S., Diolez, P., Moreau, F., Bouillaud, F., and Ricquier, D. (1990). Stable expression of functional mitochondrial uncoupling protein in Chinese hamster ovary cells. Proc. Natl. Acad. Sci. U.S.A. 87, 5124-5128.

Cypess, A. M., Lehman, S., Williams, G., Tal, I., Rodman, D., Goldfine, A. B., Kuo, F. C., Palmer, E. L., Tseng, Y. H., Doria, A., Kolodny, G. M., and Kahn, C. R. (2009). Identification and importance of brown adipose tissue in adult humans. N. Engl. J. Med. 360, 1509-1517.

Douette, P., Gerkens, P., Navet, R., Leprince, P., De, P. E., and Sluse, F. E. (2006). Uncoupling protein 1 affects the yeast mitoproteome and oxygen free radical production. Free Radic. Biol. Med. 40, 303-315.

Echtay, K. S., Bienengraeber, M., Winkler, E., and Klingenberg, M. (1998). In the uncoupling protein (UCP-1) His-214 is involved in the regulation of purine nucleoside triphosphate but not diphosphate binding. J. Biol. Chem. 273, 24368-24374.

Eckerskorn, C., and Klingenberg, M. (1987). In the uncoupling protein from brown adipose tissue the $\mathrm{C}$ terminus protrudes to the c-side of the membrane as shown by tryptic cleavage. FEBS Lett. 226, 166-170.

Enerback, S., Jacobsson, A., Simpson, E. M., Guerra, C., Yamashita, H., Harper, M. E., and Kozak, L. P. (1997). Mice lacking mitochondrial uncoupling protein are coldsensitive but not obese. Nature 387, 90-94.

Esteves, T. C., Echtay, K. S., Jonassen, T., Clarke, C. F., and Brand, M. D. (2004). Ubiquinone is not required for proton conductance by uncoupling protein 1 in yeast mitochondria. Biochem. J. 379, 309-315.

Esteves, T. C., Parker, N., and Brand, M. D. (2006). Synergy of fatty acid and reactive alkenal activation of proton conductance through uncoupling protein 1 in mitochondria. Biochem. J. 395, 619-628.

Fleury, C., Neverova, M., Collins, S., Raimbault, S., Champigny, O., LeviMeyrueis, C., Bouillaud, F., Seldin, M. F., Surwit, R. S., Ricquier, D., and Warden, C. H. (1997). Uncoupling protein-2: a novel gene linked to obesity and hyperinsulinemia. Nat. Genet. 15, 269-272.

Forest, C., Doglio, A., Ricquier, D., and Ailhaud, G. (1987). A preadipocyte clonal line from mouse brown adipose tissue. Short- and longterm responses to insulin and betaadrenergics. Exp. Cell Res. 168, 218-232.

Foster, D. O., and Frydman, M. L. (1978). Nonshivering thermogenesis in the rat. II. Measurements of blood flow with microspheres point to brown adipose tissue as the dominant site of the calorigenesis induced by noradrenaline. Can. J. Physiol. Pharmacol. 56, 110-122.

Foster, D. O., and Frydman, M. L. (1979). Tissue distribution of cold-induced thermogenesis in conscious warm- or cold-acclimated rats reevaluated from changes in tissue blood flow: the dominant role of brown adipose tissue in the replacement of shivering by nonshivering thermogenesis. Can. J. Physiol. Pharmacol. 57, 257-270.

Galetti, S., Sarre, A., Perreten, H., Produit-Zengaffinen, N., Muzzin, P., and Assimacopoulos-Jeannet, F. (2009). Fatty acids do not activate UCP2 in pancreatic beta cells: comparison with UCP1. Pflugers Arch. 457, 931-940.

Garlid, K. D., Jaburek, M., and Jezek, P. (1998). The mechanism of proton transport mediated by mitochondrial uncoupling proteins. FEBS Lett. 438, 10-14.

Garlid, K. D., Orosz, D. E., Modriansky, M., Vassanelli, S., and Jezek, P. (1996). On the mechanism of fatty acid-induced proton transport by mitochondrial uncoupling protein. J. Biol. Chem. 271, 2615-2620.

Gimeno, R. E., Dembski, M., Weng, X., Deng, N., Shyjan, A. W., Gimeno, C. J., Iris, F., Ellis, S. J., Woolf, E. A., and Tartaglia, L. A. (1997). Cloning and characterization of an uncoupling protein homolog: a potential molecular mediator of human thermogenesis. Diabetes 46, 900-906.

Gonzalez-Muniesa, P., Milagro, F. I., Campion, J., and Martinez, J. A.
(2005). Ectopic UCP1 gene expression in HepG2 cells affects ATP production. J. Physiol. Biochem. 61, 389-393.

Hagen, T., and Lowell, B. B. (2000). Chimeric proteins between UCP1 and UCP3: the middle third of UCP1 is necessary and sufficient for activation by fatty acids. Biochem. Biophys. Res. Commun. 276, 642-648.

Hany, T. F., Gharehpapagh, E., Kamel, E. M., Buck, A., Himms-Hagen, J., and von Schulthess, G. K. (2002). Brown adipose tissue: a factor to consider in symmetrical tracer uptake in the neck and upper chest region. Eur. J. Nucl. Med. Mol. Imaging 29, 1393-1398.

Harper, M. E., Monemdjou, S., Ramsey, J. J., and Weindruch, R. (1998). Age-related increase in mitochondrial proton leak and decrease in ATP turnover reactions in mouse hepatocytes. Am. J. Physiol. 275, E197E206.

Heaton, J. M. (1972). The distribution of brown adipose tissue in the human. J. Anat. 112, 35-39.

Heldmaier, G. (1971). Zitterfreie Wärmebildung und Körpergröße bei Säugetieren. Z. Vgl. Physiol. 73, 222-248.

Huang, S. G., and Klingenberg, M. (1995). Fluorescent nucleotide derivatives as specific probes for the uncoupling protein: thermodynamics and kinetics of binding and the control by $\mathrm{pH}$. Biochemistry 34 349-360.

Hughes, D. A., Jastroch, M., Stoneking, M., and Klingenspor, M. (2009). Molecular evolution of UCP1 and the evolutionary history of mammalian non-shivering thermogenesis. BMC Evol. Biol. 9, 4. doi:10.1186/1471-2148-9-4

Ivanova, M. V., Hoang, T., McSorley, F. R., Krnac, G., Smith, M. D., and Jelokhani-Niaraki, M. (2010). A comparative study on conformation and ligand binding of the neuronal uncoupling proteins. Biochemistry 49, 512-521.

Jaburek, M., and Garlid, K. D. (2003). Reconstitution of recombinant uncoupling proteins: UCP1, -2 , and -3 have similar affinities for ATP and are unaffected by coenzyme Q10. J. Biol. Chem. 278, 25825-25831.

Jastroch, M., Buckingham, J. A., Helwig, M., Klingenspor, M., and Brand, M. D. (2007). Functional characterisation of UCP1 in the common carp: uncoupling activity in liver mitochondria and cold-induced expression in the brain. J. Comp. Physiol. B $177,743-752$. 
Jezek, P., Hanus, J., Semrad, C., and Garlid, K. D. (1996). Photoactivated azido fatty acid irreversibly inhibits anion and proton transport through the mitochondrial uncoupling protein. J. Biol. Chem. 271, 6199-6205.

Jezek, P., Orosz, D. E., Modriansky, M., and Garlid, K. D. (1994). Transport of anions and protons by the mitochondrial uncoupling protein and its regulation by nucleotides and fatty acids. A new look at old hypotheses. J. Biol. Chem. 269, 26184-26190.

Jimenez-Jimenez, J., Ledesma, A., Zaragoza, P., Gonzalez-Barroso, M. M., and Rial, E. (2006). Fatty acid activation of the uncoupling proteins requires the presence of the central matrix loop from UCP1. Biochim. Biophys. Acta 1757, 1292-1296.

Keipert, S., Klaus, S., Heldmaier, G., and Jastroch, M. (2010). UCP1 ectopically expressed in murine muscle displays native function and mitigates mitochondrial superoxide production. Biochim. Biophys. Acta 1797, 324-330.

Klaus, S., Choy, L., Champigny, O., Cassard-Doulcier, A. M., Ross, S., Spiegelman, B., and Ricquier, D. (1994). Characterization of the novel brown adipocyte cell line HIB 1B. Adrenergic pathways involved in regulation of uncoupling protein gene expression. J. Cell Sci. 107(Pt 1), 313-319.

Klaus, S., Ely, M., Encke, D., and Heldmaier, G. (1995). Functional assessment of white and brown adipocyte development and energy metabolism in cell culture. Dissociation of terminal differentiation and thermogenesis in brown adipocytes. J. Cell Sci. 108(Pt 10), 3171-3180.

Klein, J., Fasshauer, M., Ito, M., Lowell, B. B., Benito, M., and Kahn, C. R. (1999). beta(3)-adrenergic stimulation differentially inhibits insulin signaling and decreases insulininduced glucose uptake in brown adipocytes. J. Biol. Chem. 274, 34795-34802.

Klingenberg, M., and Appel, M. (1989). The uncoupling protein dimer can form a disulfide cross-link between the mobile C-terminal SH groups. Eur. J. Biochem. 180, 123-131.

Klingenberg, M., and Huang, S. G. (1999). Structure and function of the uncoupling protein from brown adipose tissue. Biochim. Biophys. Acta 1415, 271-296.

Klingenberg, M., and Winkler, E. (1985). The reconstituted isolated uncoupling protein is a membrane potential driven $\mathrm{H}+$ translocator. EMBO J. 4, 3087-3092.
Klingenspor, M., and Fromme, T. (2012). "Brown adipose tissue," in Adipose Tissue Biology, 1st Edn, Vol. 6, ed. M. E. Symonds (Heidelberg: Springer), 413. Available at: http://www.springer.com/ biomed/human+physiology/book/ 978-1-4614-0964-9

Kunji, E. R., and Crichton, P. G. (2010). Mitochondrial carriers function as monomers. Biochim. Biophys. Acta 1797, 817-831.

Lean, M. E., James, W. P., Jennings, G., and Trayhurn, P. (1986a). Brown adipose tissue in patients with pheochromocytoma. Int. J. Obes. 10, 219-227.

Lean, M. E., James, W. P., Jennings, G., and Trayhurn, P. (1986b). Brown adipose tissue uncoupling protein content in human infants, children and adults. Clin. Sci. 71, 291-297.

Lee, P., Swarbrick, M. M., Zhao J. T., and Ho, K. K. (2011). Inducible brown adipogenesis of supraclavicular fat in adult humans. Endocrinology 152, 3597-3602.

Lin, C. S., Hackenberg, H., and Klingenberg, E. M. (1980). The uncoupling protein from brown adipose tissue mitochondria is a dimer. A hydrodynamic study. FEBS Lett. 113, 304-306.

Lin, C. S., and Klingenberg, M. (1980). Isolation of the uncoupling protein from brown adipose tissue mitochondria. FEBS Lett. 113, 299-303.

Lin, C. S., and Klingenberg, M. (1982). Characteristics of the isolated purine nucleotide binding protein from brown fat mitochondria. Biochemistry 21, 2950-2956.

Mercader, J., Palou, A., and Bonet, M. L. (2010). Induction of uncoupling protein-1 in mouse embryonic fibroblast-derived adipocytes by retinoic acid. Obesity (Silver Spring) 18, 655-662.

Modriansky, M., Murdza-Inglis, D. L. Patel, H. V., Freeman, K. B., and Garlid, K. D. (1997). Identification by site-directed mutagenesis of three arginines in uncoupling protein that are essential for nucleotide binding and inhibition. J. Biol. Chem. 272, 24759-24762.

Monemdjou, S., Kozak, L. P., and Harper, M. E. (1999). Mitochondrial proton leak in brown adipose tissue mitochondria of Ucpl-deficient mice is GDP insensitive. Am. J. Physiol. 276, E1073-E1082.

Montal, M., and Mueller, P. (1972). Formation of bimolecular membranes from lipid monolayers and a study of their electrical properties. Proc. Natl. Acad. Sci. U.S.A. 69, 3561-3566.

Mozo, J., Ferry, G., Masscheleyn, S., Miroux, B., Boutin, J. A., and Bouil- laud, F. (2006). Assessment of a high-throughput screening methodology for the measurement of purified UCP1 uncoupling activity. Anal. Biochem. 351, 201-206.

Murdza-Inglis, D. L., Patel, H. V., Freeman, K. B., Jezek, P., Orosz, D. E. and Garlid, K. D. (1991). Functional reconstitution of rat uncoupling protein following its high level expression in yeast. J. Biol. Chem. 266, 11871-11875.

Mzilikazi, N., Jastroch, M., Meyer, C. W., and Klingenspor, M. (2007). The molecular and biochemical basis of nonshivering thermogenesis in an African endemic mammal, Elephantulus myurus. Am. J. Physiol. Regul. Integr. Comp. Physiol. 293, R2120 R2127.

Nedergaard, J., Petrovic, N., Lindgren, E. M., Jacobsson, A., and Cannon, B. (2005). PPARgamma in the control of brown adipocyte differentiation. Biochim. Biophys. Acta 1740 293-304.

Nicholls, D. G., and Lindberg, O. (1972). Inhibited respiration and ATPase activity of rat liver mitochondria under conditions of matrix condensation. FEBS Lett. 25, 61-64.

Nicholls, D. G., and Lindberg, O. (1973). Brown-adipose-tissue mitochondria. The influence of albumin and nucleotides on passive ion permeabilities. Eur. J. Biochem. 37, 523-530.

Oelkrug, R., Kutschke, M., Meyer, C. W., Heldmaier, G., and Jastroch, M. (2010). Uncoupling protein 1 decreases superoxide production in brown adipose tissue mitochondria. J. Biol. Chem. 285, 21961-21968.

Parker, N., Crichton, P. G., Vidal-Puig, A. J., and Brand, M. D. (2009). Uncoupling protein-1 (UCP1) contributes to the basal proton conductance of brown adipose tissue mitochondria. J. Bioenerg. Biomembr. 41 , 335-342.

Pecqueur, C., Couplan, E., Bouillaud, F., and Ricquier, D. (2001). Genetic and physiological analysis of the role of uncoupling proteins in human energy homeostasis. J. Mol. Med. 79, 48-56.

Polymeropoulos, E. T., Heldmaier, G., Frappell, P. B., McAllan, B. M., Withers, K. W., Klingenspor, M., White, C. R., and Jastroch, M. (2011). Phylogenetic differences of mammalian basal metabolic rate are not explained by mitochondrial basal proton leak. Proc. Biol. Sci. doi: 10.1098/rspb.2011.0881. [Epub ahead of print].

Porter, R. K., and Brand, M. D. (1993). Body mass dependence of $\mathrm{H}+$ leak in mitochondria and its rele- vance to metabolic rate. Nature 362 , 628-630.

Puchalski, W., Bockler, H., Heldmaier, G., and Langefeld, M. (1987). Organ blood flow and brown adipose tissue oxygen consumption during noradrenaline-induced nonshivering thermogenesis in the Djungarian hamster. J. Exp. Zool. 242, 263-271.

Rial, E., Poustie, A., and Nicholls, D. G. (1983). Brown-adipose-tissue mitochondria: the regulation of the $32000-\mathrm{Mr}$ uncoupling protein by fatty acids and purine nucleotides. Eur. J. Biochem. 137, 197-203.

Ross, S. R., Choy, L., Graves, R. A., Fox, N., Solevjeva, V., Klaus, S., Ricquier, D., and Spiegelman, B. M. (1992). Hibernoma formation in transgenic mice and isolation of a brown adipocyte cell line expressing the uncoupling protein gene. Proc. Natl. Acad. Sci. U.S.A. 89, 7561-7565.

Rothwell, N. J., and Stock, M. J. (1979). A role for brown adipose tissue in diet-induced thermogenesis. Nature 281, 31-35.

Rupprecht, A., Sokolenko, E. A., Beck, V., Ninnemann, O., Jaburek, M., Trimbuch, T., Klishin, S. S., Jezek, P., Skulachev, V. P., and Pohl, E. E. (2010). Role of the transmembrane potential in the membrane proton leak. Biophys. J. 98, 1503-1511.

Saito, M., Okamatsu-Ogura, Y., Matsushita, M., Watanabe, K., Yoneshiro, T., Nio-Kobayashi, J., Iwanaga, T., Miyagawa, M., Kameya, T., Nakada, K., Kawai, Y., and Tsujisaki, M. (2009). High incidence of metabolically active brown adipose tissue in healthy adult humans: effects of cold exposure and adiposity. Diabetes 58, 1526-1531.

Schindler, H. (1979). Exchange and interactions between lipid layers at the surface of a liposome solution. Biochim. Biophys. Acta 555, 316-336.

Seale, P., Kajimura, S., Yang, W., Chin, S., Rohas, L. M., Uldry, M., Tavernier, G., Langin, D., and Spiegelman, B. M. (2007). Transcriptional control of brown fat determination by PRDM. Cell Metab. 6, 38-54.

Shabalina, I. G., Jacobsson, A., Cannon, B., and Nedergaard, J. (2004). Native UCP1 displays simple competitive kinetics between the regulators purine nucleotides and fatty acids. J. Biol. Chem. 279, 38236-38248.

Shabalina, I. G., Ost, M., Petrovic, N., Vrbacky, M., Nedergaard, J., and Cannon, B. (2010). Uncoupling protein-1 is not leaky. Biochim. Biophys. Acta 1797, 773-784. 
Shabalina, I. G., Petrovic, N., Kramarova, T. V., Hoeks, J., Cannon, B., and Nedergaard, J. (2006). UCP1 and defense against oxidative stress. 4-Hydroxy-2-nonenal effects on brown fat mitochondria are uncoupling protein 1-independent. J. Biol. Chem. 281, 13882-13893.

Si, Y., Palani, S., Jayaraman, A., and Lee, K. (2007). Effects of forced uncoupling protein 1 expression in 3T3-L1 cells on mitochondrial function and lipid metabolism. J. Lipid Res. 48, 826-836.

Skulachev, V. P. (1991). Fatty acid circuit as a physiological mechanism of uncoupling of oxidative phosphorylation. FEBS Lett. 294, 158-162.

Skulachev, V. P. (1996). Role of uncoupled and non-coupled oxidations in maintenance of safely low levels of oxygen and its one-electron reductants. Q. Rev. Biophys. 29, 169-202.

Smith, R. E. (1961). Thermogenic activity of the hibernating gland in the cold-acclimated rat. Physiologist 4, 113.

Stuart, J. A., Harper, J. A., Brindle, K. M., Jekabsons, M. B., and Brand, M. D. (2001). A mitochondrial uncoupling artifact can be caused by expression of uncoupling protein 1 in yeast. Biochem. J. 356, 779-789.

Svensson, P. A., Jernas, M., Sjoholm, K., Hoffmann, J. M., Nilsson, B. E., Hansson, M., and Carlsson, L. M.
(2011). Gene expression in human brown adipose tissue. Int. J. Mol. Med. 27, 227-232.

Symonds, M. E., Budge, H., Perkins, A C., and Lomax, M. A. (2011). Adipose tissue development - impact of the early life environment. Prog. Biophys. Mol. Biol. 106, 300-306.

Taga, H., Chilliard, Y., Meunier, B., Chambon, C., Picard, B., Zingaretti, M. C., Cinti, S., and Bonnet, M. (2011). Cellular and molecular large-scale features of fetal adipose tissue: is bovine perirenal adipose tissue brown? J. Cell. Physiol. doi: 10.1002/jcp.22893. [Epub ahead of print].

Trayhurn, P., and James, W. P. (1978). Thermoregulation and nonshivering thermogenesis in the genetically obese (ob/ob) mouse. Pflugers Arch. 373, 189-193.

Uldry, M., Yang, W., St-Pierre, J., Lin, J., Seale, P., and Spiegelman, B. M. (2006). Complementary action of the PGC-1 coactivators in mitochondrial biogenesis and brown fat differentiation. Cell Metab. 3, 333-341.

Urbankova, E., Voltchenko, A., Pohl, P., Jezek, P., and Pohl, E. E. (2003). Transport kinetics of uncoupling proteins. Analysis of UCP1 reconstituted in planar lipid bilayers. J. Biol. Chem. 278, 32497-32500. van Marken Lichtenbelt, W. D., Vanhommerig, J. W., Smulders, N. M. Drossaerts, J. M., Kemerink, G. J., Bouvy, N. D., Schrauwen, P., and Teule, G. J. (2009). Cold-activated brown adipose tissue in healthy men. N. Engl. J. Med. 360, 1500-1508.

Virtanen, K. A., Lidell, M. E., Orava, J., Heglind, M., Westergren, R., Niemi, T., Taittonen, M., Laine, J., Savisto, N. J., Enerback, S. and Nuutila, P. (2009). Functional brown adipose tissue in healthy adults. N. Engl. J. Med. 360, 1518-1525

Winkler, E., and Klingenberg, $\mathrm{M}$. (1994). Effect of fatty acids on $\mathrm{H}+$ transport activity of the reconstituted uncoupling protein. J. Biol. Chem. 269, 2508-2515.

Winkler, E., Wachter, E., and Klingenberg, M. (1997). Identification of the $\mathrm{pH}$ sensor for nucleotide binding in the uncoupling protein from brown adipose tissue. Biochemistry 36, 148-155.

Zilberfarb, V., Pietri-Rouxel, F., Jockers, R., Krief, S., Delouis, C., Issad, T., and Strosberg, A. D. (1997). Human immortalized brown adipocytes express functional beta3adrenoceptor coupled to lipolysis. $J$. Cell. Sci. 110(Pt 7), 801-807.

Zingaretti, M. C., Crosta, F., Vitali, A., Guerrieri, M., Frontini, A., Cannon, B., Nedergaard, J., and
Cinti, S. (2009). The presence of UCP1 demonstrates that metabolically active adipose tissue in the neck of adult humans truly represents brown adipose tissue. FASEB J. 23, 3113-3120.

Conflict of Interest Statement: The authors declare that the research was conducted in the absence of any commercial or financial relationships that could be construed as a potential conflict of interest.

Received: 31 August 2011; paper pending published: 21 September 2011; accepted: 12 October 2011; published online: 08 November 2011.

Citation: Hirschberg $V$, Fromme $T$ and Klingenspor $M$ (2011) Test systems to study the structure and function of uncoupling protein 1: a critical overview. Front. Endocrin. 2:63. doi: 10.3389/fendo.2011.00063

This article was submitted to Frontiers in Cellular Endocrinology, a specialty of Frontiers in Endocrinology.

Copyright (c) 2011 Hirschberg, Fromme and Klingenspor. This is an open-access article subject to a non-exclusive license between the authors and Frontiers Media $S A$, which permits use, distribution and reproduction in other forums, provided the original authors and source are credited and other Frontiers conditions are complied with. 